\title{
Managing Both Strength and Ductility in Duplex Stainless Steel with Heterogeneous Lamella Structure
}

\author{
Xie, Lin; Huang, Tianlin; Zhang, Ling; Cao, Wenquan; Wu, Guilin; Huang, Xiaoxu
}

Published in:

Materials Science and Engineering: A - Structural Materials: Properties, Microstructure and Processing

Link to article, DOI:

10.1016/j.msea.2018.09.085

Publication date:

2018

Document Version

Peer reviewed version

Link back to DTU Orbit

Citation (APA):

Xie, L., Huang, T., Zhang, L., Cao, W., Wu, G., \& Huang, X. (2018). Managing Both Strength and Ductility in Duplex Stainless Steel with Heterogeneous Lamella Structure. Materials Science and Engineering: $A$ - Structural Materials: Properties, Microstructure and Processing, 738, 190-193. https://doi.org/10.1016/j.msea.2018.09.085

\section{General rights}

Copyright and moral rights for the publications made accessible in the public portal are retained by the authors and/or other copyright owners and it is a condition of accessing publications that users recognise and abide by the legal requirements associated with these rights.

- Users may download and print one copy of any publication from the public portal for the purpose of private study or research.

- You may not further distribute the material or use it for any profit-making activity or commercial gain

- You may freely distribute the URL identifying the publication in the public portal 
Managing Both Strength and Ductility in Duplex Stainless Steel with Heterogeneous

\section{Lamella Structure}

Lin Xie ${ }^{\text {a }}$, Tianlin Huang ${ }^{\text {a }}$, Ling Zhang ${ }^{\text {a, } * \text {, Wenquan Cao }}{ }^{\mathrm{b}}$, Guilin $\mathrm{Wu}^{\mathrm{a}}{ }^{\mathrm{a} *}$, X. Huang a, c

${ }^{\text {a } I n t e r n a t i o n a l ~ J o i n t ~ L a b o r a t o r y ~ f o r ~ L i g h t ~ A l l o y s ~(M O E), ~ C o l l e g e ~ o f ~ M a t e r i a l ~ S c i e n c e ~ a n d ~}$ Engineering, Chongqing University, Chongqing 400044, China

${ }^{\mathrm{b}}$ Special Steel Institute, Central Iron and Steel Research Institute, Beijing 100081, China

c Department of Mechanical Engineering, Technical University of Denmark, DK-2500 Lyngby, Denmark

Corresponding author: Guilin Wu (G.L. Wu)

Email: wugl@cqu.edu.cn

Address: College of Material Science and Engineering, Chongqing University

Shazhengjie 174, Shapingba District,

Chongqing 400044

China

\section{Declarations of interest: none!}

Authors' contributions: GW and XH designed the experiments. XL, TH and LZ did the experiment and analysed experimental data. WC provided the material. XL, WG and XH wrote the manscript. All authors contributed the discussions. 
Managing Both Strength and Ductility in Duplex Stainless Steel with Heterogeneous

\title{
Lamella Structure
}

Lin Xie ${ }^{\text {a }}$, Tianlin Huang ${ }^{\text {a }}$, Ling Zhang ${ }^{\text {a, } * \text {, Wenquan Cao }}{ }^{\mathrm{b}}$, Guilin $\mathrm{Wu}^{\mathrm{a}}{ }^{\mathrm{a} *}$, X. Huang a, c

${ }^{\text {a }}$ International Joint Laboratory for Light Alloys (MOE), College of Material Science and Engineering, Chongqing University, Chongqing 400044, China

${ }^{\mathrm{b}}$ Special Steel Institute, Central Iron and Steel Research Institute, Beijing 100081, China

c Department of Mechanical Engineering, Technical University of Denmark, DK-2500 Lyngby, Denmark

* Corresponding author: zhangling2014@ cqu.edu.cn (L. Zhang)

** Corresponding author: wugl@cqu.edu.cn (G.L. Wu)

\begin{abstract}
A commercial 2507 duplex stainless steel with heterogeneous lamella structures was prepared by cold-rolling and appropriate annealing. A yield strength of $800 \mathrm{MPa}$, a tensile strength of $1000 \mathrm{MPa}$ and a uniform elongation of $20 \%$ were achieved in the sample after $90 \%$ cold rolling following by annealing at $900^{\circ} \mathrm{C}$ for $1 \mathrm{~min}$. The origin of the excellent mechanical properties was discussed by microstructural features and the evolution of backstress.
\end{abstract}

Keywords: Duplex stainless steel; mechanical properties; heterogeneous lamella structure; back stress; strain hardening

\section{Introduction}


It is well recognized that the strength of conventional metals can be dramatically increased by refining grain size to sub-micrometer or nanometer scale. However, the losing of tensile ductility of the ultrafine grained (UFG) or nanocrystalline metals can very hard to be avoided. The low ductility is believed to be caused by the limited capacity of work hardening in small grains. Several strategies have been developed to improve ductility of nanostructured metals, such as introducing of fine particles, gradient structures from coarse to fine grains and introducing of grains with nanotwins [1].

Recently, heterogeneous lamella (HL) structures [2] have been paid special attentions. The essence of this strategy is to produce materials with alternative distribution of coarse grained (CG) lamella and UFG lamella. The high work hardening capacity of coarse grains and high strength of fine grains can make the materials strong and ductile. Pioneering study has been conducted by $\mathrm{Wu}$ et al. [3], where a HL-Ti was produced by making use of slight structure gradient caused by asymmetric rolling and partial recrystallization. Later, Zhang et al. [4] achieved a more complicated L2 structure, that is, hierarchical layer + heterogeneous lamella structure, in an IF steel by mechanical stacking of plates with different grain size scales. Both HL-Ti and L2-IF steel exhibit outstanding mechanical properties including both UFG strength and CG ductility. These achievements clearly offer a new scope for microstructural designing of metals.

The present study proposes another method to produce a HL structure in metals. The idea is to apply deformation and annealing to duplex stainless steels (DSSs). When these kinds of steels are deformed, i.e. rolling, a layered duplex structure can be produced. The differences in thermal stability between two phases can lead to different recover and recrystallization behaviors in the following annealing [5]. By careful controlling of annealing conditions, a HL structure consisting of ultrafine grains and coarse grains can be obtained. The propose of the present experimental is to prepare a layered duplex steel with HL structures and reveal its mechanical properties. 


\section{Experimental procedure}

A commercial 2507 DSS plate has been chosen to study for its wide application and also as a model alloy with two phases with about equal volume fractions. The alloy was received in solution-annealed and quenched condition, with chemical composition of $<0.02 \% \mathrm{C}, 6.3 \%$ $\mathrm{Ni}, 24.6 \% \mathrm{Cr}, 0.3 \% \mathrm{~N},<0.33 \% \mathrm{Si},<0.03 \% \mathrm{P},<0.01 \% \mathrm{~S}$, and the balance $\mathrm{Fe}$ (mass $\%$ ). A 10 mm thick sheet was cut from the plate and cold rolled to a thickness reduction of $90 \%$, followed by annealing at temperatures from $900-1000^{\circ} \mathrm{C}$ for $1 \mathrm{~min}$.

Microstructural characterizations were carried out by electron backscatter diffraction (EBSD) and transmission electron microscopy (TEM) techniques. Samples for microstructural characterizations were prepared from the longitudinal section containing the rolling direction (RD) and normal direction (ND). EBSD mapping was conducted using a JSM 7800F scanning electron microscope, with a step size of $100 \sim 500 \mathrm{~nm}$. Specimens for EBSD observation were first mechanically polished and then electrochemically polished in an electrolyte of 15 vol.\% perchloric acid and 85 vol.\% acetic acid with a voltage of $15 \mathrm{~V}$ at room temperature. TEM characterizations were carried out with a JEOL 2100 TEM operated at an accelerate voltage of $200 \mathrm{kV}$. Thin foils for TEM observation were prepared by mechanical polishing to a thickness of $70 \mu \mathrm{m}$, followed by electropolishing using a twin-jet polisher in a solution of $25 \mathrm{vol} . \%$ perchloric acid and $75 \mathrm{vol} . \%$ ethanol with a voltage of $20 \mathrm{~V}$ at $-20^{\circ} \mathrm{C}$.

Mechanical properties of samples were characterized by uniaxial tensile tests including monotonic tensile loading and tensile-unloading-reloading (TUR) tests, which were carried out with a MTS793 testing system. Tensile specimens of gauge dimensions $25 \times 5 \mathrm{~mm}^{2}$ were machined from the sheets along the RD and tested at a quasi-static rate of $6 \times 10^{-4} \mathrm{~s}^{-1}$ at room temperature. For the TUR test, five unloading-reloading were conducted. The specimen was 
unloaded at a pre-designed strain by the stress-control mode to $20 \mathrm{~N}$ at the unloading rate of $200 \mathrm{~N} \cdot \mathrm{min}^{-1}$, and then reloaded to the same applied stress before the next cycle.

\section{Results and discussion}

Fig. 1 shows the EBSD image of the as-received sample, in which the irregular austenite islands randomly distributed in the matrix of ferrite. It is a typical CG duplex structure with an average grain size of $10.7 \mu \mathrm{m}$ for austenite and $19.2 \mu \mathrm{m}$ for ferrite. The austenite grains are mainly enclosed by high angle boundaries (HABs) including twin boundaries (TBs), while the ferrite grains are separated by both low and high angle boundaries (LABs and HABs).

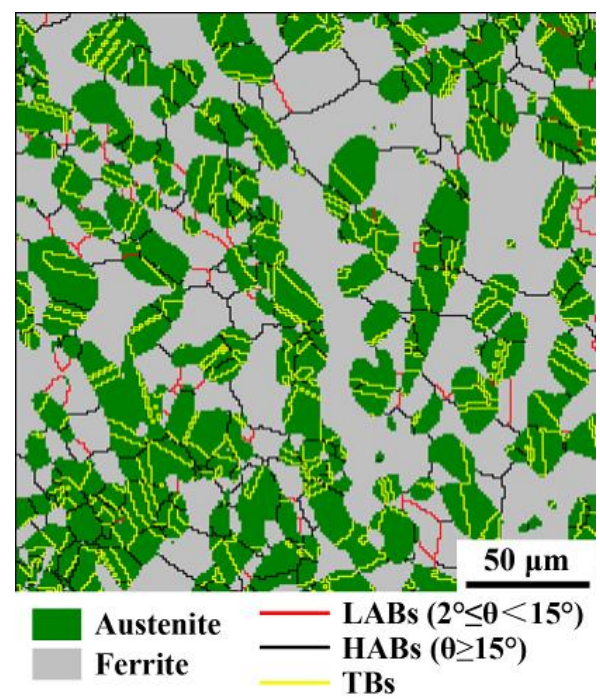

Figure 1 EBSD image of the as-received sample.

Fig. 2 shows the EBSD maps of the samples cold rolled and annealed at $900-1000^{\circ} \mathrm{C}$ for 1 min, respectively. The morphology of phases is inherited from the preceding rolling process, showing a refined, alternating layered structure of austenite and ferrite. The average boundary spacing of phase interfaces are $6.4 \mu \mathrm{m}$ for the $900^{\circ} \mathrm{C}$ annealed sample, $6.6 \mu \mathrm{m}$ for the $950^{\circ} \mathrm{C}$ annealed sample and $7.9 \mu \mathrm{m}$ for the $1000^{\circ} \mathrm{C}$ annealed sample. The austenite exhibits an extended recovered or recrystallized structure consisted of equiaxed fine grains, most of 
which contain annealing twins. Its average grain size is $0.9 \mu \mathrm{m}$ for the $900^{\circ} \mathrm{C}$ annealed sample, $1.1 \mu \mathrm{m}$ for the $950^{\circ} \mathrm{C}$ annealed sample and $1.4 \mu \mathrm{m}$ for the $1000^{\circ} \mathrm{C}$ annealed sample. However, the ferrite reveals a partially recrystallized structure. Some of recrystallized grains grow into a coarse, elongated shape, which run parallel to phase boundaries forming a bamboo shaped lamella. On the other hand, most of un-recrystallized ultrafine grain matrix, mainly enclosed by LABs, still remain in a small size scale. The average grain sizes of coarse grains and ultrafine grains, taking the $900^{\circ} \mathrm{C}$ annealed sample for example, are $6.9 \mu \mathrm{m}$ and $0.8 \mu \mathrm{m}$, respectively. As the temperature elevates up to $1000^{\circ} \mathrm{C}$, the bamboo shaped lamella becomes more pronounced. The volume fraction of coarse grains increases from $17.6 \%$ to $38.5 \%$, accompanied by a structural coarsening. In some ferrite layers, the recrystallized grains even expanded to the full thickness of the phase layer. Therefore, the annealed structures are typical HL structures. The heterogeneity mainly manifests in two aspects. First, the duplex structure is consisted of austenite and ferrite that have different crystalline structures. Furthermore, the ferrite is characterized by both coarse grained lamella and ultrafine subgrains matrix that possess different mechanical properties.

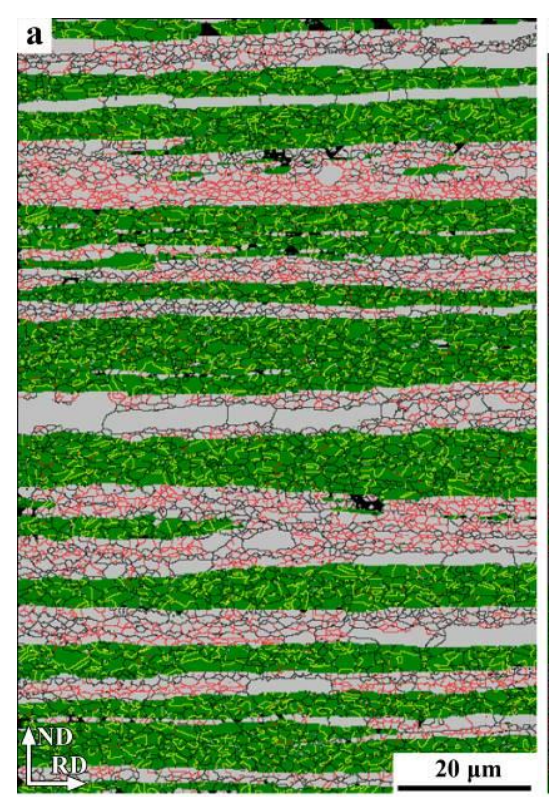

Austenite
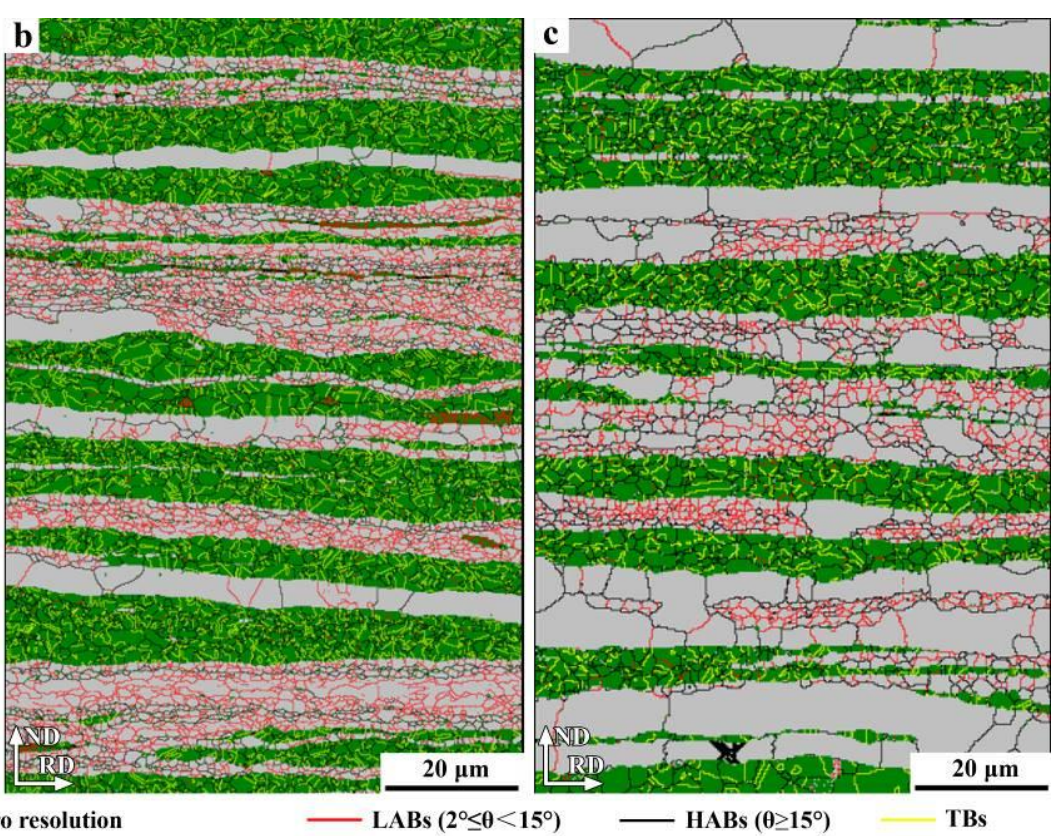
Figure 2 EBSD images of the samples cold rolled and annealed at (a) $900^{\circ} \mathrm{C}$, (b) $950^{\circ} \mathrm{C}$ and (c) $1000^{\circ} \mathrm{C}$ for $1 \mathrm{~min}$.

Fig. 3 shows representative engineering stress-strain curves of the annealed samples and, for comparison, of the as-received sample. Improved combinations of strengths and ductilities can be observed in the annealed samples. Especially for the $900^{\circ} \mathrm{C}$ annealed one, the yield and tensile strengths are increased to $800 \mathrm{MPa}$ and $1000 \mathrm{MPa}$ as compared to $480 \mathrm{MPa}$ and 700 $\mathrm{MPa}$ of the as-received sample, respectively. More important, the uniform elongation of the $900^{\circ} \mathrm{C}$ annealed sample is rarely deteriorated, which is $23 \%$ as compared to $28 \%$ of the asreceived sample. It should be pointed out that the yield strength and uniform elongation of commercial $2507 \mathrm{DSS}$ are usually 500-650 $\mathrm{MPa}$ and 20-25\%, respectively [6,7], as the present initial material. The present DSS sample with a HL structure $\left(900^{\circ} \mathrm{C}\right.$ annealed) clearly shows a superior strength-ductility combination.

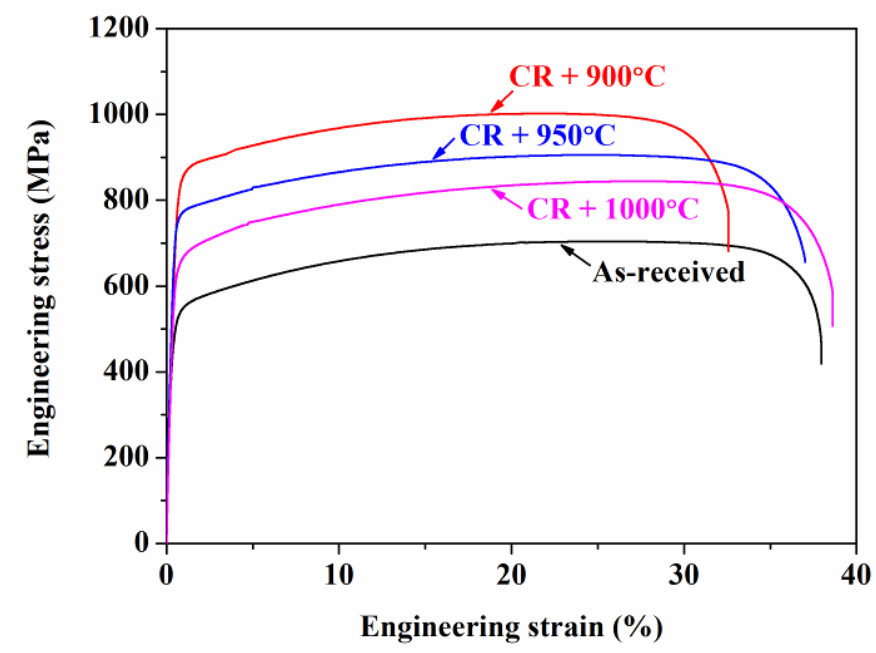

Figure 3 Engineering stress-strain curves of the samples cold rolled and annealed.

For the present DSS, austenite usually has higher hardness than ferrite due to its high nitrogen content [8] and a smaller average grain size. Under plastic deformation, the ferrite 
will deform preferentially, results in a large accumulation of dislocations along phase boundaries, which further leads to the generation of geometrically necessary dislocations (GNDs) to accommodate the strain incompatibility between the two phases [9-10]. This produces a long-range back stress [11-12] to make it difficult for dislocations to transfer from ferrite to neighboring austenite until the latter starts to yield at a larger total strain, and as a result, it strengthens DSS.

To further probe the contribution of back stress to the mechanical properties of duplex HL structure, the TUR test was carried out on the $900^{\circ} \mathrm{C}$ annealed sample. Fig. 4a shows the TUR true stress-strain curve of the sample investigated. The inset in this figure clearly reveals a hysteresis loop during the unloading-reloading cycle, indicating a strong Bauschinger effect [13]. The determination of back stress from the tensile unloading-reloading hysteresis loop is described in detail elsewhere [14]. In the present case, as shown in Fig. 4b, the back stress $\left(\sigma_{\text {back }}\right)$ is estimated to be $360 \mathrm{MPa}$ at the tensile strain of 0.02 and it increases up to $518 \mathrm{MPa}$ after tensile strain of 0.1. More notably, the back stress exhibits a high strain hardening rate $\left(\Theta_{\text {back }}\right)$, which is even higher than the total strain hardening rate $\left(\Theta_{\text {Total }}\right)$ at the early stage of tensile deformation. The significant back stress and its work hardening can be attributed to the unique features of the duplex HL structure. The fabrication of this structure is accompanied by a significant structural refinement, resulting in a high density of phase interfaces, which is favorable for developing GNDs near phase boundaries that elevates back stress [Error! Bookmark not defined.]. Moreover, the duplex HL structure makes it possible for back stress develops at the interfaces not only between dissimilar phases but also between soft coarse grains and the hard ultrafine grains in ferrite [2]. 

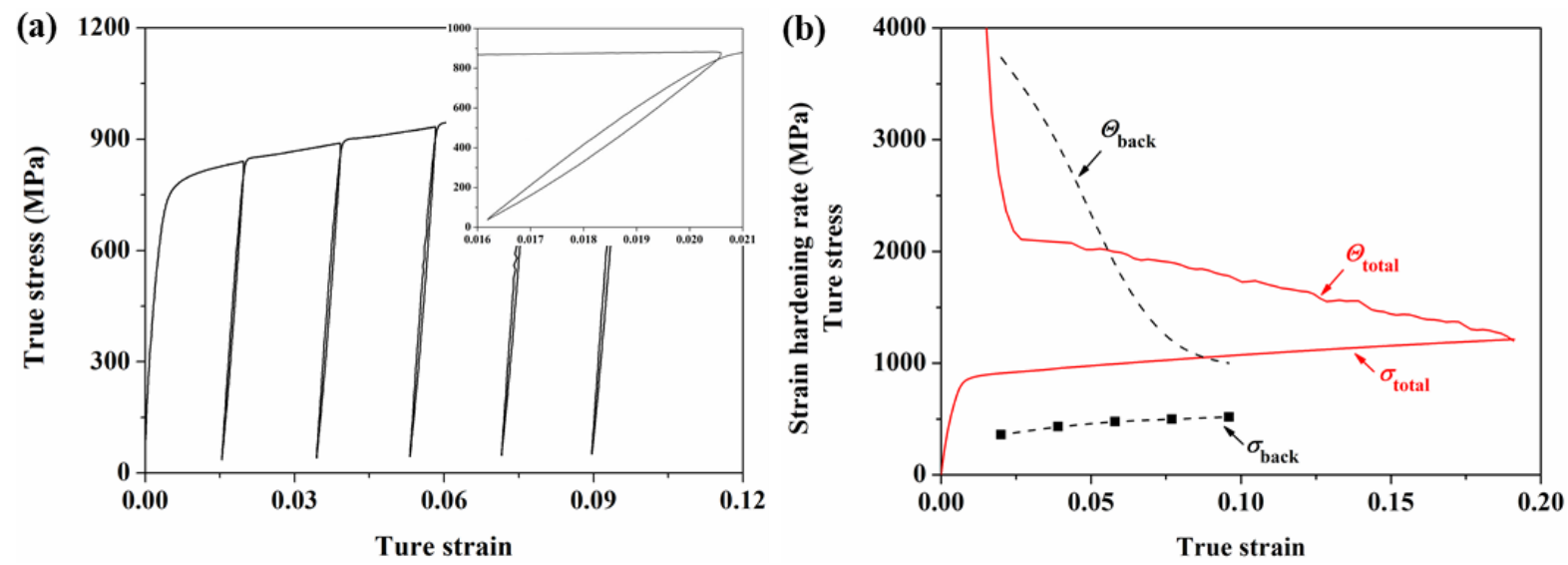

Figure 4 (a) The CTUR true stress-strain curve of the $900^{\circ} \mathrm{C}$ annealed sample; (b) Back stress and its strain hardening.

Fig. 5 shows the TEM images of the $900^{\circ} \mathrm{C}$ annealed sample after tensile strain of $1 \%$, where the structural heterogeneity is taken into account. As shown in Fig. 5a, a typical structure at a phase boundary can be observed. It is seen that dislocations are mainly piled up at the ferrite side along the phase boundary, while the austenite is characterized by deformation twins, which is proved by the electron diffraction pattern inserted. This clearly reveals the difference in plastic response between austenite and ferrite. For the ferrite, typical structures in a large recrystallized grain and a fine non-recrystallized (yet recovered) grain are shown in Fig. 5b and c, respectively. The recrystallized ferrite is characterized by a huge amount of dislocations (Fig. 5b), which are in forms of dislocation tangles and dislocation boundaries [15]; while for the non-recrystallized ferrite, there are much less dislocations statistically stored in the grain (Fig. 5c). In this stage, the imposed strain on grains is mainly relaxed by the formation of dislocation configurations such as dislocation cells and cell blocks $[15,16]$. Coarse grains are therefore favorable for evolving such substructures, causing the increase in the work hardening rate with strain. On the other hand, fine grains can retain most of the strengthening effect by grain refinement. 

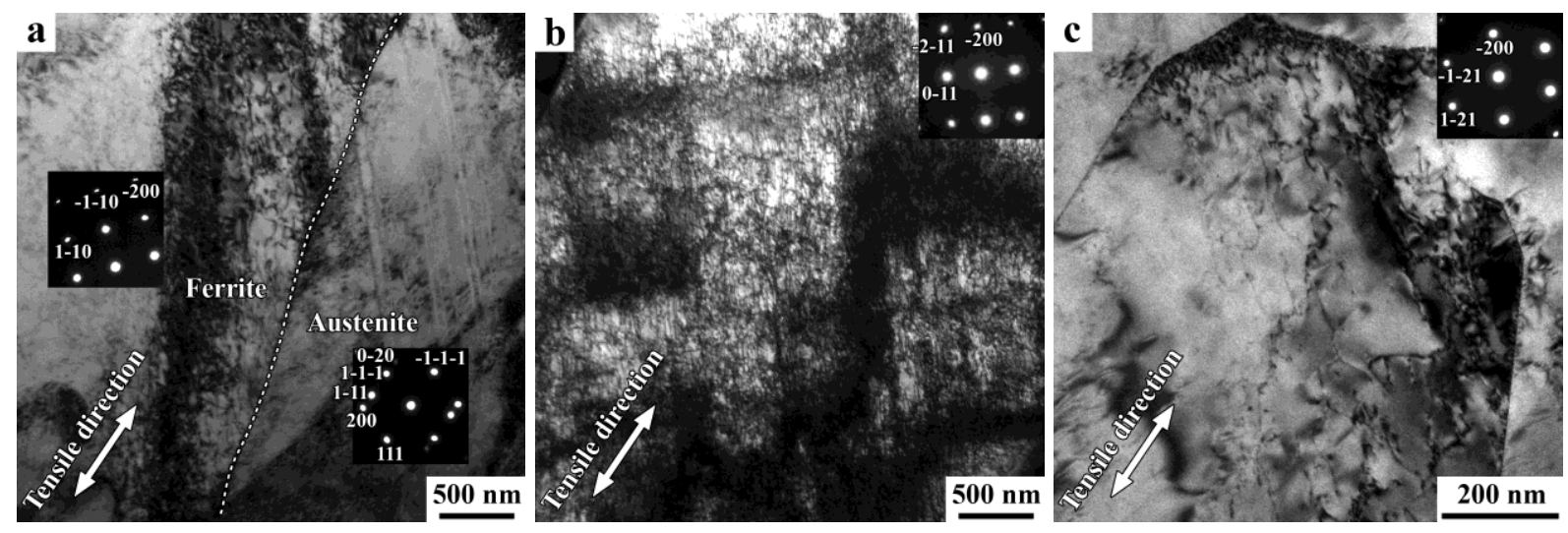

Figure 5 TEM images revealing the deformed microstructures of the $900^{\circ} \mathrm{C}$ annealed sample after tensile strain of $1 \%$. (a) at phase boundary; (b) in coarse ferrite grain; (c) in fine ferrite grain

The effect of duplex HL structure on mechanical behavior can be summarized into three aspects. First is the duplex structure with inhomogeneous distribution of grain. The full constraint of the soft phase by the hard phase makes it effective to constrain the plastic deformation of the soft phase to develop back stress that contributes to strain hardening [2]. Similar situation is also existed between UFG matrix and CG inclusions. Second, the lamella morphology can produce higher strain hardening than equiaxed ones, especially when its long axis is parallel to the loading direction [17]. This structural geometry makes mutual constraint between the dissimilar phases more effective, which can produce higher back stress [3]. Finally, the duplex HL structure has the high density of phase interfaces, where dislocations can pile up and accumulate to enhance the evolution of the back stress.

\section{Conclusions}

Commercial 2507 DSS with heterogeneous lamella (HL) structures was produced by cold rolling and subsequent annealing. Significant improvement of mechanical properties is achieved. The main conclusions are summarized as follows: 
(i) The duplex HL structure is characterized by alternative austenite and ferrite layers, in which the ferrite is composing of coarse (micron scale) grained lamella and fine (submicron scale) grained matrix.

(ii) The alloy with a duplex HL structure shows an excellent combination of strength and ductility. The yield strength and tensile elongation are increased up to $800 \mathrm{MPa}$ and $23 \%$ as compared to $480 \mathrm{MPa}$ and $28 \%$ of its coarse-grained counterpart, respectively.

(iii) The excellent mechanical properties can be attributed to the structural refinement and the evolution of back stress arising from the strain incompatibility across the interfaces between different structural components.

\section{Acknowledgements}

This project was financially supported by the State Key Research and Development Program of MOST, China (2016YFB0700401, 2016YFB0700403) and National Natural Science Foundation of China (NSFC, Nos.: 51471039 and 51671039) and Fundamental Research Funds for the Central Universities (No. 2018CDJDCL0019).

\section{Data availability}

The raw/processed data required to reproduce these findings are available after request to the corresponding author.

\section{References}

[1] K. Lu, Stabilizing nanostructures in metals using grain and twin boundary architectures, Nat. Rev. Mater., 19 (2016) 1-13.

[2] X.L. Wu, Y.T. Zhu, Heterogeneous materials: a new class of materials with unprecedented mechanical properties, Mater. Res. Lett., 5 (2017) 527-532. 
[3] X.L. Wu, M.X. Yang, F.P. Yuan, G.L. Wu, Y.J. Wei, X.X. Huang, Y.T. Zhu, Heterogeneous lamella structure unites ultrafine-grain strength with coarse-grain ductility, Proc. Natl. Acad. Sci. USA, 112 (2015) 14501-14505.

[4] L. Zhang, Z. Chen, Y.H. Wang, G.Q. Ma, T.L. Huang, G.L. Wu, D.J. Jensen, Fabricating interstitial-free steel with simultaneous high strength and good ductility with homogeneous layer and lamella structure, Scr. Mater., 141 (2017) 111-114.

[5] J. Keichel, J. Foct, G. Gottstein. Deformation and annealing behavior of nitrogen alloyed duplex stainless steels, ISIJ Int., 43 (2003) 1788-1794.

[6] C. Sanmarchi, B.P. Somerday, J. Zelinski, X. Tang, G.H. Schiroky, Metall. Mater. Trans. A, 38 (2007) 2763-2775.

[7] R. Lin Peng, G. Chai, N. Jia, Y. D. Wang, S. Johansson, Micromechanical interactions in a superduplex stainless steel subjected to low cycle fatigue loading, Fatigue Fract. Engng. Mater. Struct., 31 (2008) 892-901.

[8] Y. Cao, Y.B. Wang, X.H. An, X.Z. Liao, M. Kawasaki, S.P. Ringer, T.G. Langdon, Y.T. Zhu, Concurrent microstructural evolution of ferrite and austenite in a duplex stainless steel processed by high-pressure torsion, Acta Mater., 63 (2014) 16-29.

[9] H. Mughrabi, On the role of strain gradients and long-range internal stresses in the composite model of crystal plasticity, Mater. Sci. Eng. A 317 (2001) 171-180.

[10] L. Chen, F.P. Yuan, P. Jiang, J.J. Xie, X.L. Wu, Simultaneous improvement of tensile strength and ductility in micro-duplex structure consisting of austenite and ferrite, Mater. Sci. Eng. A, 618 (2014) 563-571.

[11] H. Mughrabi, Dislocation wall and cell structures and long-range internal stresses in deformed metal crystals, Acta Metall. 31 (1983) 1367-1379.

[12] J.C. Gibeling, W.D. Nix, A numerical study of long range internal stresses associated with subgrain boundaries, Acta Metall. 28 (1980) 1743-1752. 
[13] R. Sowerby, D. K. Uko, A Review of Certain Aspects of the Bauschinger Effect in Metals, Mater. Sci. Eng., 41 (1979) 43-58.

[14] M.X. Yang, Y. Pan, F.p. Yuan, Y.T. Zhu, X.L. Wu, Back stress strengthening and strain hardening in gradient structure, Mater. Res. Lett., 4 (2016) 145-151.

[15] L.F. Zhang, R.B. Song, C. Zhao, F.Q. Yang, Work hardening behavior involving the substructural evolution of an austenite-ferrite Fe-Mn-Al-C steel, Mater. Sci. Eng. A, 640 (2015) 225-234.

[16] H.R. Abedi, A. Zarei Hanzaki, K.L. Ou, Ch.H. Yu, Substructure hardening in duplex low density steel, Mater. Des. 116 (2017) 472-480.

[17] K. Tanaka, T. Mori, The hardening of crystals by non-deforming particles and fibres, Acta Metall. 18 (1970) 931-941. 